\title{
PHAEOCHROMOCYTOMATA IN CHILDREN
}

\author{
BY \\ DOUGLAS HUBBLE \\ From the Derbyshire Hospital for Sick Children
}

(Received for Publication January 8, 1951)

The occurrence of a phaeochromocytoma in a child has not apparently been reported in the English literature. There are now reports in the world literature of at least 14 cases in children under the age of 14 years in whom the diagnosis was made during life. Twelve of these children were operated upon; nine of them were cured by surgery but three died.

Cahill (1948) has operated on three such children, and in two of his cases the operation was successful. In one case, a tumour was discovered at operation in a child of 2 years of age (Neff, Tice, Walker, and Ockerblad, 1942), but the other 13 children were between the ages of 10 and 15 years when the diagnosis was made. It is, however, notable that although the diagnosis in these 13 children was not made until after they were 10 years old, yet in ten of them the symptoms had begun between the ages of 6 and 8 years. With increasing awareness of the symptom-complex, it may be assumed that diagnosis will be made earlier with an improved chance of survival for these children.

Hypertension in children occurs in renal disease, in acrodynia (pink disease), in coarctation of the aorta, in lead poisoning, and in phaeochromocytomata. These diseases can usually be differentiated by clinical and laboratory examination, and the diagnosis of phaeochromocytomata in children should be easier than it is in adults in whom the distinction from essential hypertension constitutes a major diagnostic problem. Where renal failure supervenes on hypertension, the distinction from primary renal disease is undeniably difficult in children as in adults, and in one reported case in a child, this caused considerable delay in making the diagnosis of phaeochromocytoma (Koffler, Buck, Wingard, Hitchcock, Guthrie, and Teague, 1950).

The following case report concerns a boy who had four tumours, one in each adrenal, and two smaller ones in the para-aortic chromaffin tissue, and who died following a laparotomy.

\section{Case Report}

M.B., aged $11 \frac{1}{2}$, was admitted to the wards of the Derbyshire Hospital for Sick Children on August 3, 1950, from the Out-patient Department, where he had been referred by his doctor, Dr. G. S. N. Dow, for an opinion on his cardiac condition. The history of his illness went back to the age of $6 \frac{1}{2}$ years, when he began to have recurrent attacks of acute abdominal pain, accompanied by vomiting. His family doctor noted that the attacks of pain were associated with great sweating, and that while the attacks were occurring the pulse rate was very rapid, and the temperature was raised to $99^{\circ}$. The high pulse rate was not maintained after the attack, but there was a persistent systolic murmur in the mitral area. Attacks of sweating also occurred unassociated with pain. In June, 1945, he developed intermittent nocturnal enuresis.

He complained of pain in the eyes and photophobia in February, 1946, and he was seen by Mr. T. E. A. Carr, and later also by Mr. C. H. Bamford in consultation. Mr. Carr's report on January 26, 1946, is as follows:

'Pupil reactions normal: R.V. $=6 / 60$ L.V. $=6 / 60$. Right fundus, massive exudate at posterior pole involving disc of which the position can only be located by the direction of the larger retinal vessels, which are themselves largely obscured by the very unusually dense exudate. There are a few small outlying patches of exudate. Down and out, old (inactive) patches of scar tissue with pigment deposits can be seen.

' Left fundus, similar to right, but the massive exudate is mostly to the nasal side of the disc, of which the form can be made out fairly well. Old scars (fibrotic and pigmented) are seen temporarily. There was no sign of vascular disease in the fundi.'

In view of the ophthalmological suggestion that papilloedema might be concealed by the massive exudate, the child was admitted for lumbar puncture and radiography of the skull. X-ray examination was negative. The pressure of the cerebrospinal fluid appeared normal, but there was insufficient for actual measurement; examination of the fluid showed eight polymorphonuclear cells and 22 lymphocytes with $66 \mathrm{mg}$. \% protein.

He was observed in the Out-patient Department until June, 1947, when he ceased to attend. During this time, his attacks of abdominal pain ceased, and his general condition improved; he gained $9 \mathrm{lb}$. (weight, $56 \mathrm{lb}$. at the 
age of 8 ). The retinal lesion was noted to be regressing, the exudative retinopathy disappeared, and some of the fibrous scars had cleared. There were white areas suggestive of choroidal sclerosis, and a few small patches of pigment were seen in each retina with some pale spots at each macula. Vision was $6 / 60$ in the right eye and less than $6 / 60$ in the left.

During the following three years he did not attend the hospital, but he was stated by his parents to have been very well, and to have attended school regularly. $\mathrm{He}$ had, however, continued to be nervous, and sweated a great deal. He was very active, but on occasional days he appeared fatigued. He was taken to see Mr. Affleck Greeves in July, 1949, who, in December, 1950, gave this retrospective opinion concerning his findings in the light of the subsequent diagnosis.

'I find it difficult to associate the fundus changes in this case with the presence of a phaeochromocytoma, with the exception of the narrowing of the retinal arteries which was extremely evident. The changes were primarily choroidal, and without any signs of recent activity. They consisted of fairly extensive atrophic patches in the choroid, such as one finds as the result of a severe inflammatory affection, and there was in addition an organized strand of old inflammatory exudate in the right macula. It is true that in one of Bruce's cases two minute areas of old choroiditis were observed in one eye in addition to the retinopathy, but in my opinion these were not necessarily of any significance, because such patches are frequently found in the peripheral fundus of otherwise perfectly normal eyes.'

Examination and Investigation. The boy was both restless and active; he was usually pale, but when under examination his face, hands, and feet became a bright red. He would then sweat profusely. His intake of fluid varied between 3 and 5 pints daily, and his output between 20 and $35 \mathrm{oz}$. daily. It was not thought that his consumption of food was excessive. His weight was $71 \mathrm{lb}$. (a gain of $19 \mathrm{lb}$. in the previous three years), and his height $4 \mathrm{ft} .7 \frac{1}{2}$ in. Pubic and axillary hair was beginning to grow. His temperature was normal, subnormal, or was sometimes between $99^{\circ}$ and $100^{\circ}$.

An examination of the cardiovascular system showed that his pulse rate varied between 96 and 130 a minute. His heart was enlarged, the apex beat was in the fifth space in the anterior axillary line. There was a systolic thrill at the apex. There was a loud systolic mitral murmur, a rough systolic murmur at the base, maximal in the aortic area and conducted into the neck, and a diastolic murmur conducted down the sternum. The brachial, radial, and femoral arteries appeared hard, and there was good pulsation in the femoral arteries. The blood pressure taken on scores of occasions varied between 150 to 240 systolic and 100 to 130 diastolic.

The heart shadow portrayed a large heart, and the enlargement in both the postero-anterior view and the second oblique view was demonstrated to be due to the left ventricle (Figs. 1 and 2). The aorta was unfolded, but there was no calcification. There was no notching of the ribs and no pulmonary congestion.

The retinoscopy showed a few areas of fibrosis and pigmentation in both fundi. The retinal arteries were. extremely attenuated.

The sodium amytal test (Fig. 3), grains $1 \frac{1}{2}$ repeated twice at one-hour intervals, gave no evidence of marked. lability of blood pressure.

In the benzodioxane (piperoxane hydrochloride) test. (Fig. 4), M.B. required $12 \mathrm{mg}$. (The dose of benzodioxane is calculated on the surface area of the patient, the usual adult dose being $20 \mathrm{mg}$. The patient is put under the basic conditions, and an intravenous normal saline drip is. set up. Twenty to 30 minutes is allowed for the blood pressure to become stabilized, then three blood pressure readings are recorded at intervals of two to three minutes. The last readings are taken 1 minute and 30 seconds before injection of the benzodioxane. The solution is injected slowly over two minutes. After the injection, the blood pressure is taken at one-minute intervals for 10 to 15 minutes. If the hypertension is associated with an adrenaline-producing chromaffin tumour, a drop of 20 to $50 \mathrm{~mm}$. in both diastolic and systolic pressures occurs within four minutes, while the pressure returns to its pre-injection levels in about 15 minutes.) The positive result in M.B. is shown in the graph (Fig. 4).

The electrocardiograms (Fig. 5) showed an inversion of $T$ waves in the classic leads II and III, while in the unipolar chest leads there was inversion of the $T$ waves in all leads, indicative of left ventricular strain.

The urine showed no albumen, red cells, or casts. The blood urea was $35 \mathrm{mg}$. \% and urea clearance showed $105 \%$ of normal function. The urine concentration and dilution test was normal (1022-1002).

The intravenous pyelograms were normal except for some slight distortion of the superior calyx on the left side.

The perirenal insufflation of air (Fig. 6) produced good pictures only of the left renal area (Mr. A. J. Wilson and Dr. G. Q. Chance). During this examination the boy became ill with symptoms we had learnt to recognize as hyperadrenalinism-sweating, tachycardia, rise of blood pressure, and collapse-which required the discontinuance of the examination. There was an area of increased density in the left kidney above the superior calyx. This shadow was not regarded as sufficiently diagnostic of a tumour to justify exploration of the left adrenal, especially in view of the failure on the right side.

An examination of his carbohydrate metabolism showed that there was transient glycosuria, and the fasting blood sugar level was $140 \mathrm{mg}$. \%. The glucose tolerance curve after $50 \mathrm{~g}$. of glucose showed:

\begin{tabular}{|c|c|c|c|c|}
\hline$\frac{1}{2}$ hour & & & & $165 \mathrm{mg} . \%$ \\
\hline hour & . & . & ${ }^{\circ}$ & $165 \mathrm{mg} . \%$ \\
\hline$\frac{1}{2}$ hours & - & . & • & $120 \mathrm{mg} . \%$ \\
\hline hours & $\cdots$ & . & . & $120 \mathrm{mg} . \%$ \\
\hline
\end{tabular}

The blood count was as follows: Hb. $108 \%$, R.B.C.s 4,990,000 per c.mm., C.I. $1 \cdot 1$, W.B.C.s 16,000 per c.mm. (eosinophils $3 \%$, old metamyelocytes $8 \%$, neutrophils $73 \%$, lymphocytes $15 \%$, monocytes $1 \%$ ). Red cells and platelets were normal.

Dr. A. M. Hain, of the Department of Obstetrics and Gynaecology, University of Manchester, on September 3, 1950, made the following report: 


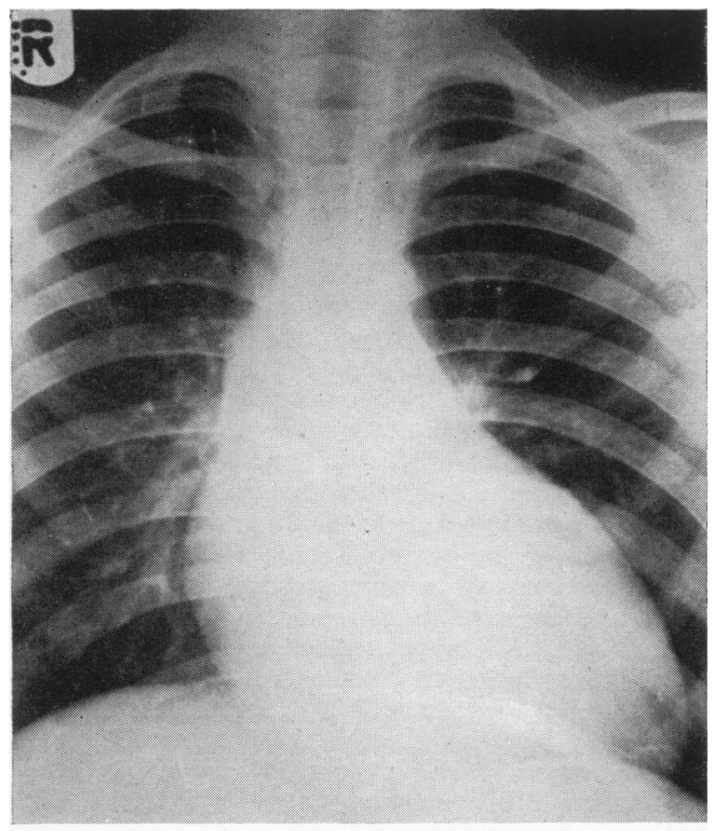

FIG. 1.
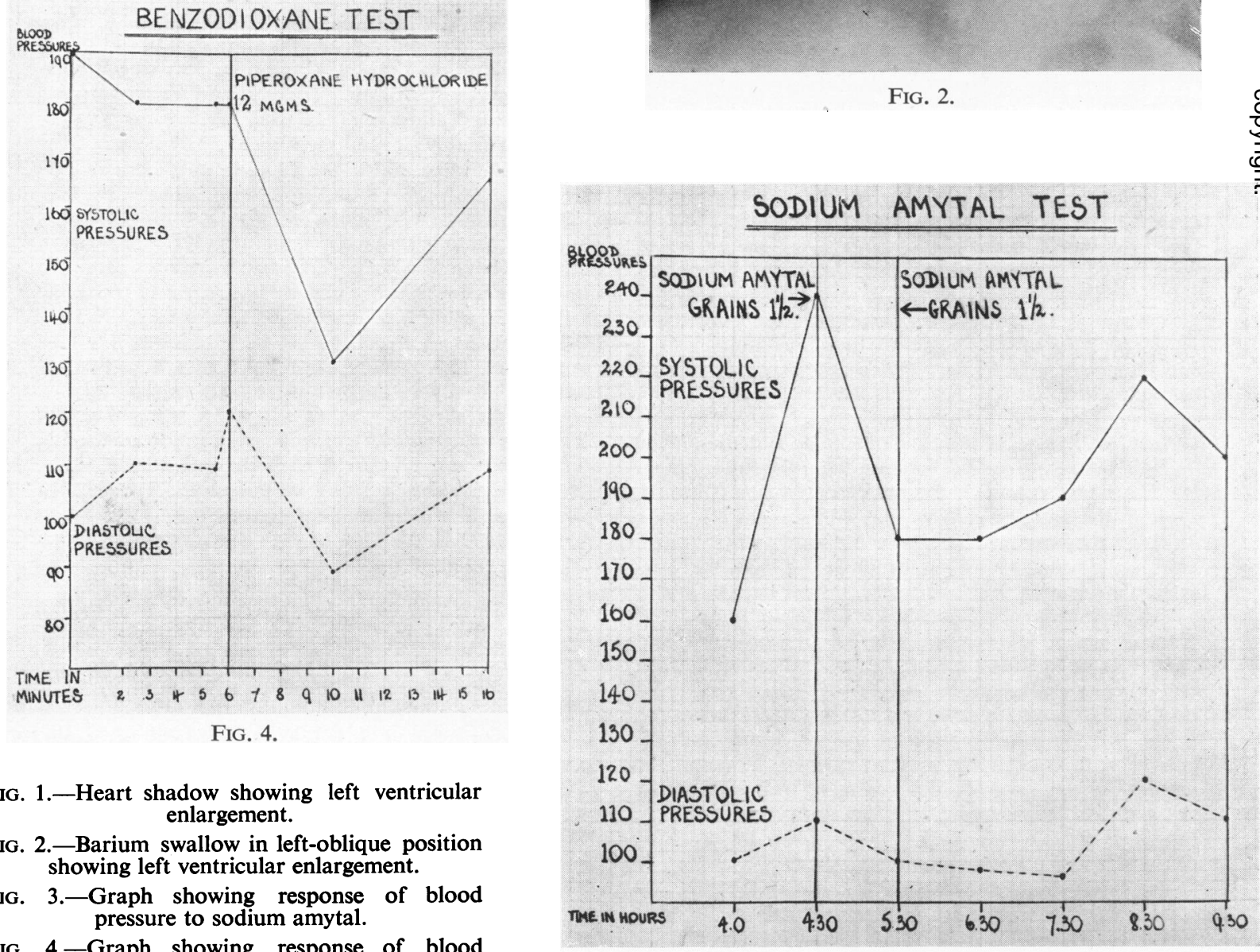

FIG. 3.

FIG. 4.

FIg. 1.-Heart shadow showing left ventricular enlargement.

FIg. 2.-Barium swallow in left-oblique position showing left ventricular enlargement.

FIG. 3.-Graph showing response of blood pressure to sodium amytal.

FIG. 4.-Graph showing response of blood pressure to benzodioxane. 

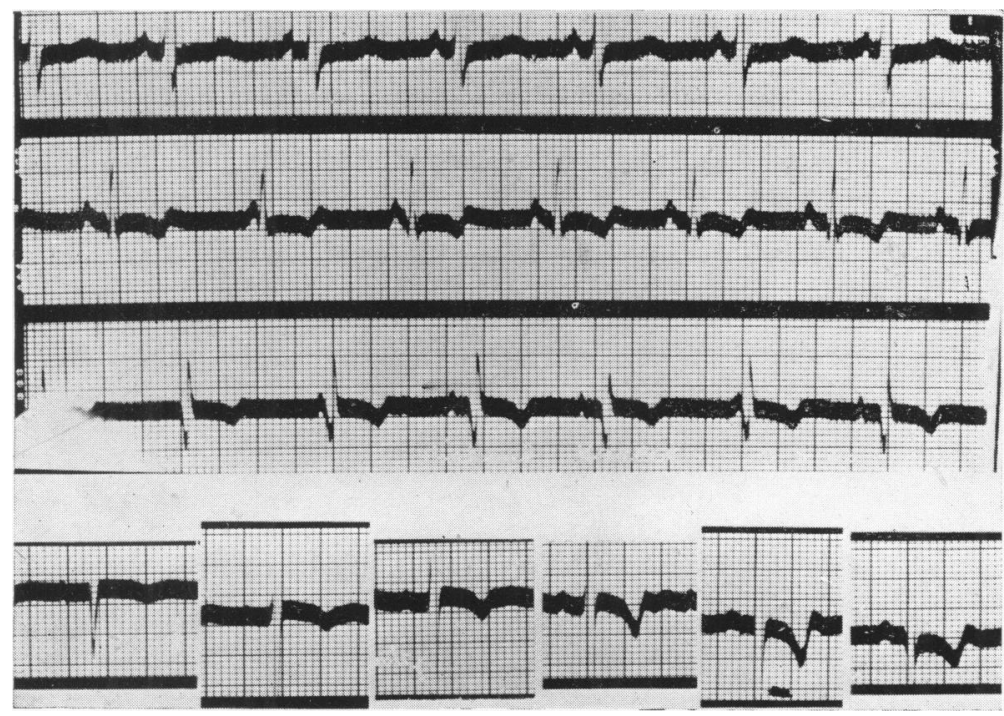

FIG. 5.-Electrocardiograms of leads I, II, III and V, I-VI. Inverted T Waves in leads II and III and V, I-VI. Left axis deviation with vertical heart.

' 17 -Ketosteroids, $3.7 \mathrm{mg}$. in 24 hours; gonadotrophins, merely a trace (about 2 or 3 M.U. in 24 hours). These values suggest hypopituitarism, as both of them are low for a boy who is nearly 12 years old. He should be excreting about 5 or $6 \mathrm{mg}$. of 17-ketosteroids in 24 hours.'

All other investigations, including cerebrospinal fluid and radiography of the skull, were normal.

Diagnosis. A diagnosis of phaeochromocytoma producing hypertension, arteriosclerosis, and coronary ischaemia was made with confidence on these findings. In view of the comparative failure of the $x$-ray examination by perirenal air, it was decided that a diagnostic laparotomy should be made. This was done on September 13, 1950, by Mr. A. J. Wilson under gas, oxygen, and $10 \mathrm{mg}$. of curare, given by Dr. R: Bliss. The blood pressure before the operation was 180 systolic, 110 diastolic. It rose to 220/154 during the induction.

A hard tumour was discovered in the right adrenal, and a suspicious smaller tumour was felt apparently in the area of the tail of the pancreas. The cardiac rate increased from 160 in the induction period to 180 per minute during the operation. While the tumour on the left side was palpated, the pressure rose to $230 / 170$, and while the tumour on the right side was palpated, the pressure rose to $236 / 180$. At the end of the operation, the pressure was $220 / 140$, and the heart rate was 164 per minute. It was intended that the tumour (or tumours) should be removed at a later date. However, this intention was prevented as the boy died seven hours after the operation. His blood pressure rose to $210 / 150$ again one hour after the operation, but thereafter fell steadily to $150 / 110$ rising to $160 / 130$ half an hour before death. His pulse rate varied between 140 and 160 per minute. He was conscious, cooperative, and not cyanosed during this time, and was taking fluids by mouth. He became

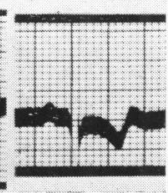

unconscious with muscular twitching at 5 p.m., and died 10 minutes later. His death was presumably the result of vasomotor stress upon a cardiovascular system already damaged by hyperadrenalinism.

Necropsy Report. Necropsy was performed by Dr. I. Mackenzie on September 14, 1950, 17 hours after death.

The meninges were normal. There was a fair degree of atheroma in the vessels at the base of the brain, but the brain showed no organic disease apart from hyperaemia.

Examination of the cardiovascular system showed that there was an enlarged pericardial cavity containing a large heart, but no excess of fluid. The weight of the heart empty was $14 \frac{1}{2}$ oz. The valves were functionally competent. There was marked hypertrophy of the left ventricular wall, the muscle being of apparent good quality and $3 \mathrm{~cm}$. in thickness. Atheroma was present in the coronary vessels and could

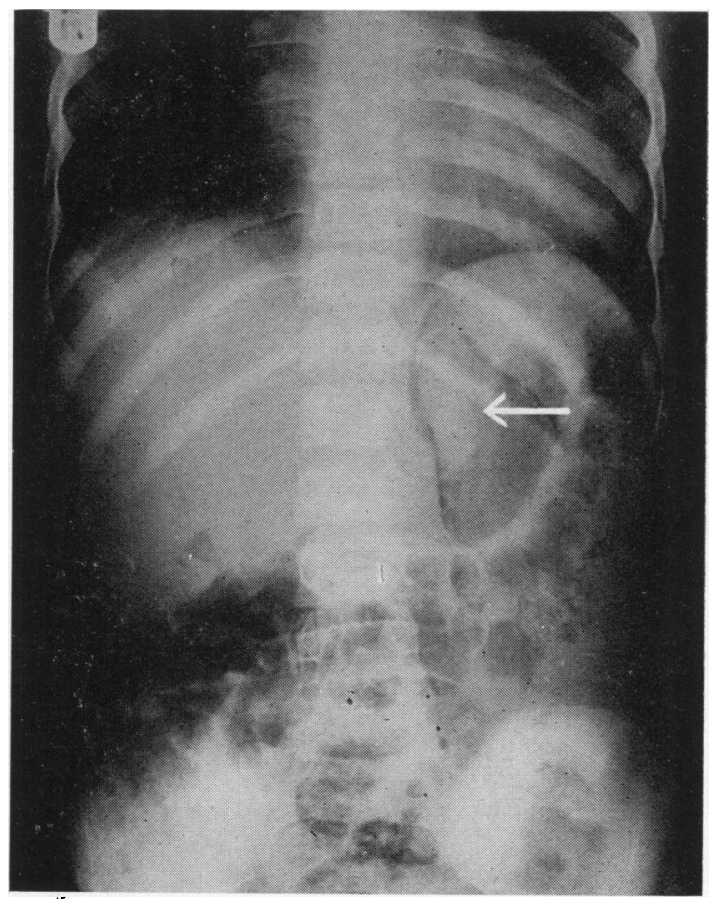

Fig. 6.-Perirenal insufflation of air showing an area of increased density over superior calyx in the left kidney. 

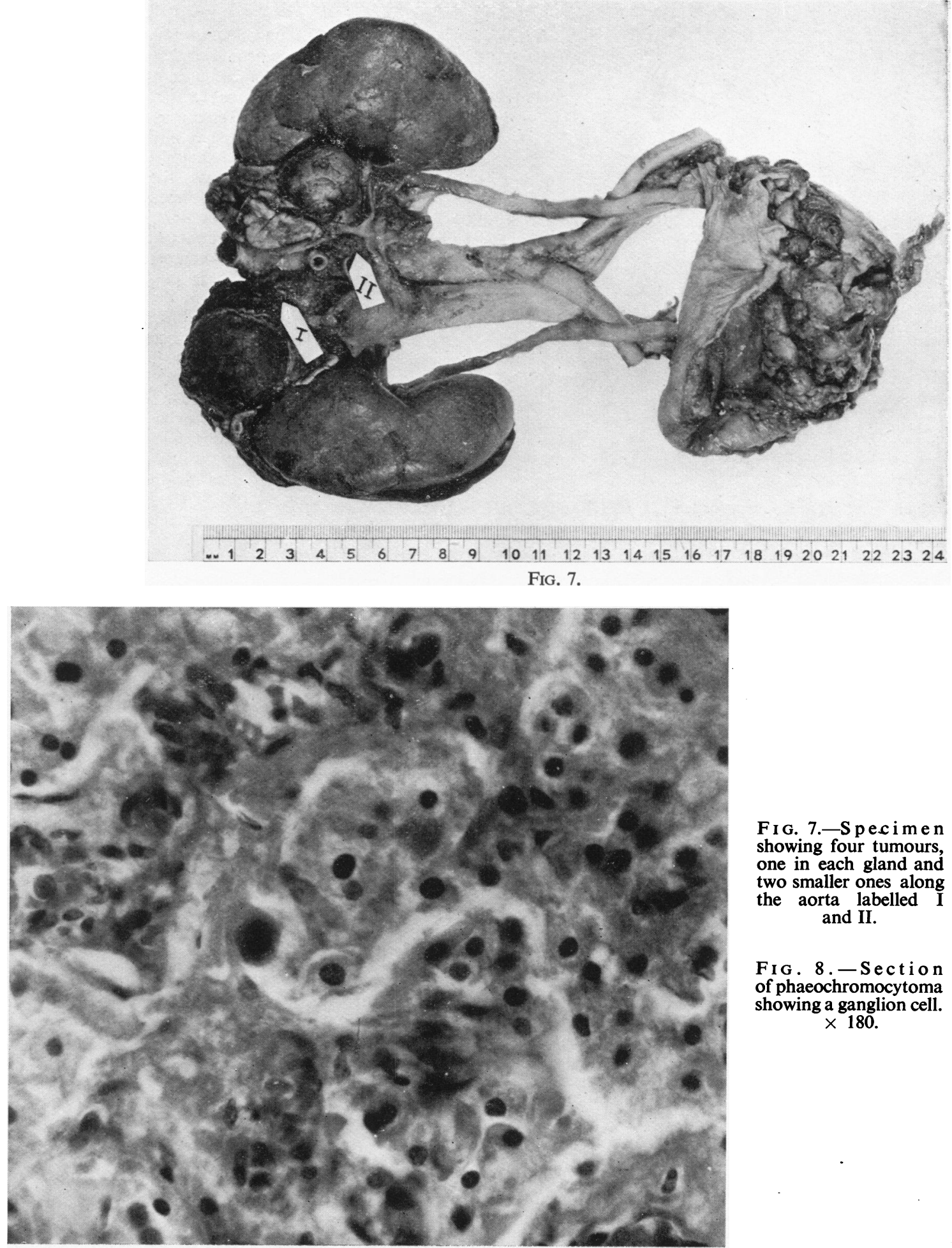

Fig. 7.-S p e.c i men showing four tumours, one in each gland and two smaller ones along the aorta labelled I and II.

FIG. 8.-Section of phaeochromocytoma showing a ganglion cell. $\times 180$.

FIG. 8. 
be discerned by the naked eye, but there was a considerable degree of atheromatous change in the carotid and aorta. The iliac arteries were hard even to the touch.

In the adrenals there was a tumour present in each gland. The right tumour was roughly spherical and measured $3 \times 3 \times 2.8 \mathrm{~cm}$. in its widest measurement. It had a pale grey-red centre and appeared to be encapsulated. The centre was continuous with the chromaffin tissue in the medulla of the remnants of normal adrenal gland. This tumour was situated at the upper aspect of the adrenal. The left adrenal tumour was more ovoid in shape, and was confined to the lower pole of the adrenal in coming over the upper pole of the kidney and half of the renal pelvis. It was $2.8 \mathrm{~cm}$. in its widest measurement and $1.6 \mathrm{~cm}$. in its narrowest. There was very little adrenal tissue of normal appearance on the left side. The tumours had the naked eye appearance of phaeochromocytomata. There were also at least two accessory tumours of similar nature, one situated on the anterior aspect of the aorta on the right side in close relation to the right adrenal tumour, and another on the anterior aspect of the aorta. A search was made for the organ of Zuckerkandl and for other remnants of chromaffin tissue around the aorta and along the carotid vessels, but none was found (Fig. 7).

Histological Examination. Microscopically the tumour consisted of loose bundles of cells lying in close relation to vascular channels supported by firm fibrovascular stroma (Fig. 8). The cells were mainly spherical in shape and fairly uniform in size. Some cells were polyhedral, and others had ill-defined borders, but the nuclei were comparatively large and stained well. No mitoses were seen. There was a faint attempt at acinar grouping of the cells, but few collections were to be observed in such formation. The chromaffin reaction was exhibited in many cells. This consists of brown granules within the cytoplasm of certain of the chromaffin cells in bichromate fixed tissue. It was visible not only in unstained sections, but could be seen in the haematoxylin and eosin and Giemsa-stained slides. It showed to advantage in the latter. Not all the typical cells showed these granules, and the intensity of granule formation varied from cell to cell in those which did stain. There were certain cells which showed a resemblance to sympathetic ganglion cells, but distribution was not general throughout the tissue. The fibrovascular stroma was very well marked, and all the bundles of cells lay in close relation to capillaries. One area of the tumour was particularly richly supplied with vessels. Many large arteries could be discerned running through the tissue. The fibrous stroma was also well developed, and was accompanied by an increase in both pericellular and periacinar reticulin (Fig. 9).

Sections of the myocardium showed typical hypertrophy (Fig. 9) of the muscle as in hypertensive heart disease, and the vessels running in the myocardium showed advanced subintimal proliferation and reduplication of elastic tissue (Fig. 10). The anterior descending branch of the left coronary artery showed formation of atheroma accompanied by necrosis in the deeper part of the subintimal layer. Vessels containing cholesterol

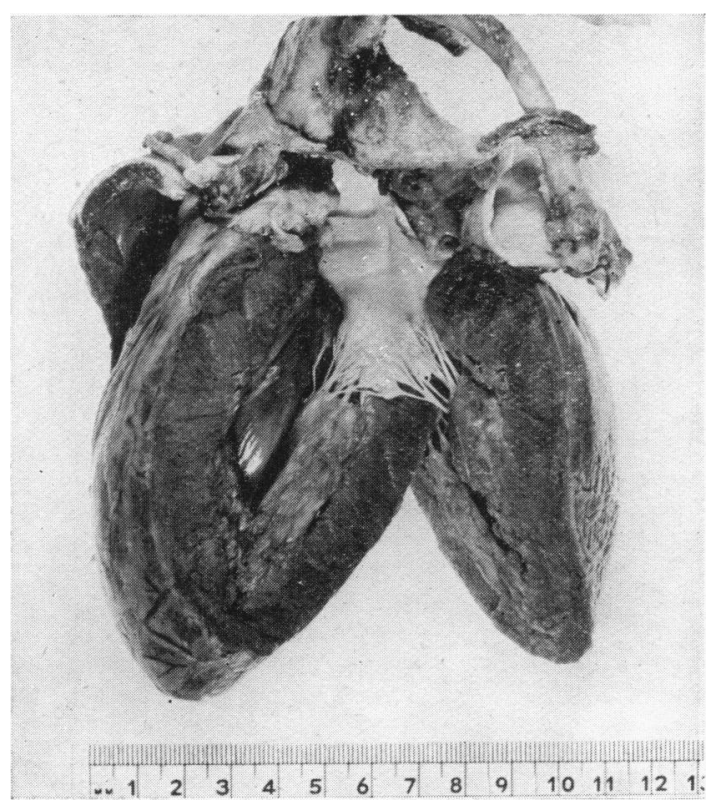

FIG. 9.-Heart showing hypertrophied left ventricle.

clefts were frequent and accompanied by a great reduction in the size of the lumen of the vessel (Fig. 11). The coronary vessels also showed reduplication of elastic tissue. The carotid arteries and aorta showed similar changes of lesser intensity, and this change was also present in the splenic arterioles although the spleen showed no gross lesion other than passive venous congestion.

The kidneys did not appear to be extensively involved, the main lesions consisting of a prominence of the glomerular lining membrane and a mild degree of tufting of the unit. There were, however, certain glomeruli filled with red cells, and showing focal embolic nephritis. Others showed advanced necrosis with a fibroblastic reaction in the surrounding renal parenchyma.

The arteries showed moderate subintimal hypertrophy which was continued down into arterioles. The cause of the focal embolic lesions appeared to be essentially vascular, and might have been entirely due to local increase in subintimal hypertrophy in an arteriole (Fig. 12). The sections of the eye showed signs indicating old haemorrhagic exudate in the subchoroid layer (Fig. 13). There were many macrophages around the vessels containing haemosiderin. There were one or two small areas of imperfect calcification or bone formation near the scleral junction, and this indicated former disease in this vicinity. There was also the possibility of a subretinal exudate having occurred in this eye, reduced by the fact that this was an eye removed at necropsy and the changes might be due to inadequate fixation. The vessels, however, showed marked reduplication of the elastic lamina similar to those obtaining in the carotid and coronary arteries. The adrenal cortex was normal, all three zones being well differentiated. 


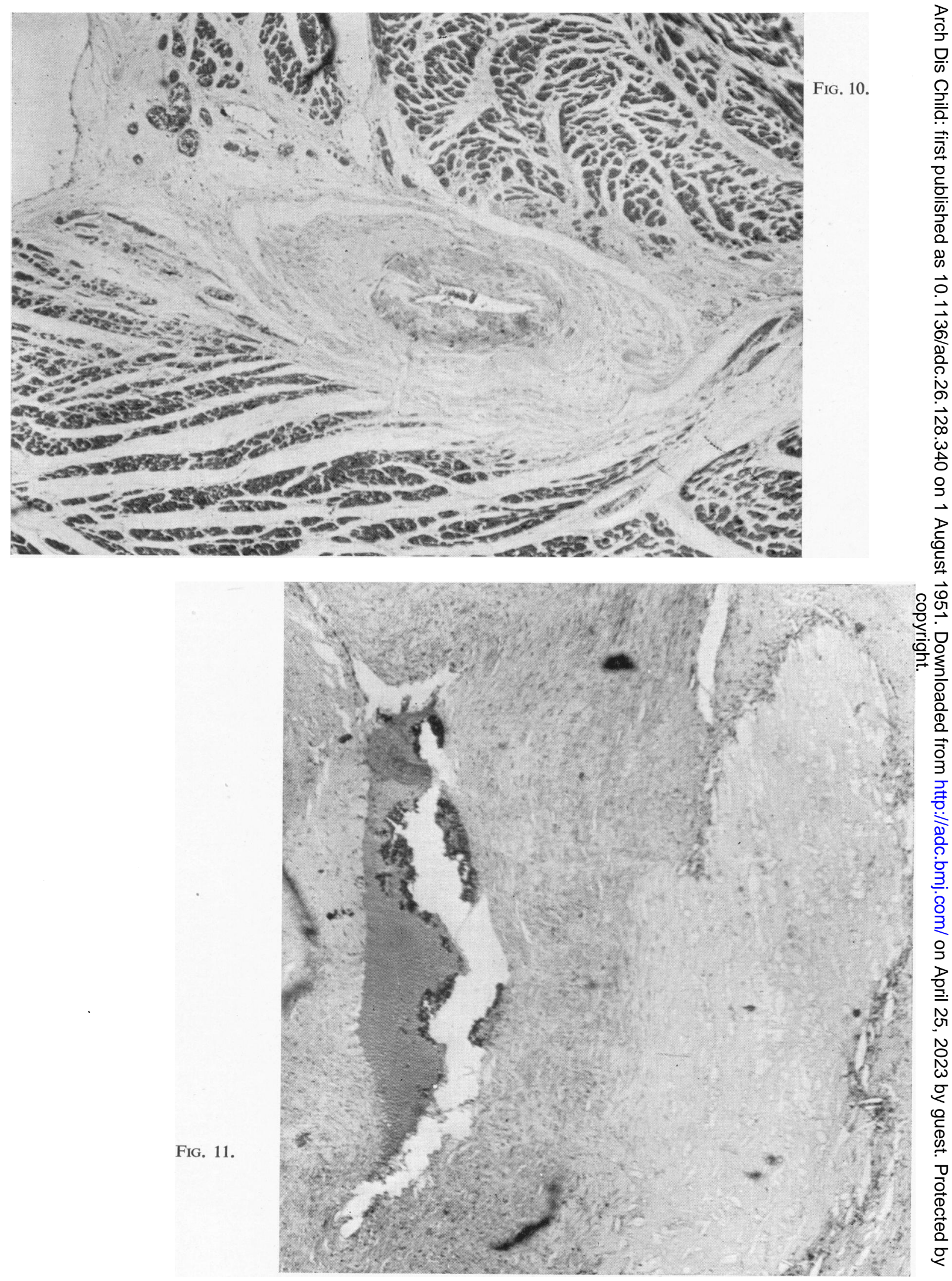


FIG. 10.-Hyperplastic arteriole in myocardium. $\times 200$.

Fig. 11.-Anterior branch of left coronary artery showing numerous cholesterol clefts and subintimal hyperplasia. $\quad \times 150$.

Fig. 12.-Focal embolic nephritis showing glomerulus stuffed with red cells. $\times 180$.

Fig. 13.-Section of the eye showing reduplication of the elastic lamina in arteriole and old haemorrhagic exudate in subchoroid layer. $\times 800$.

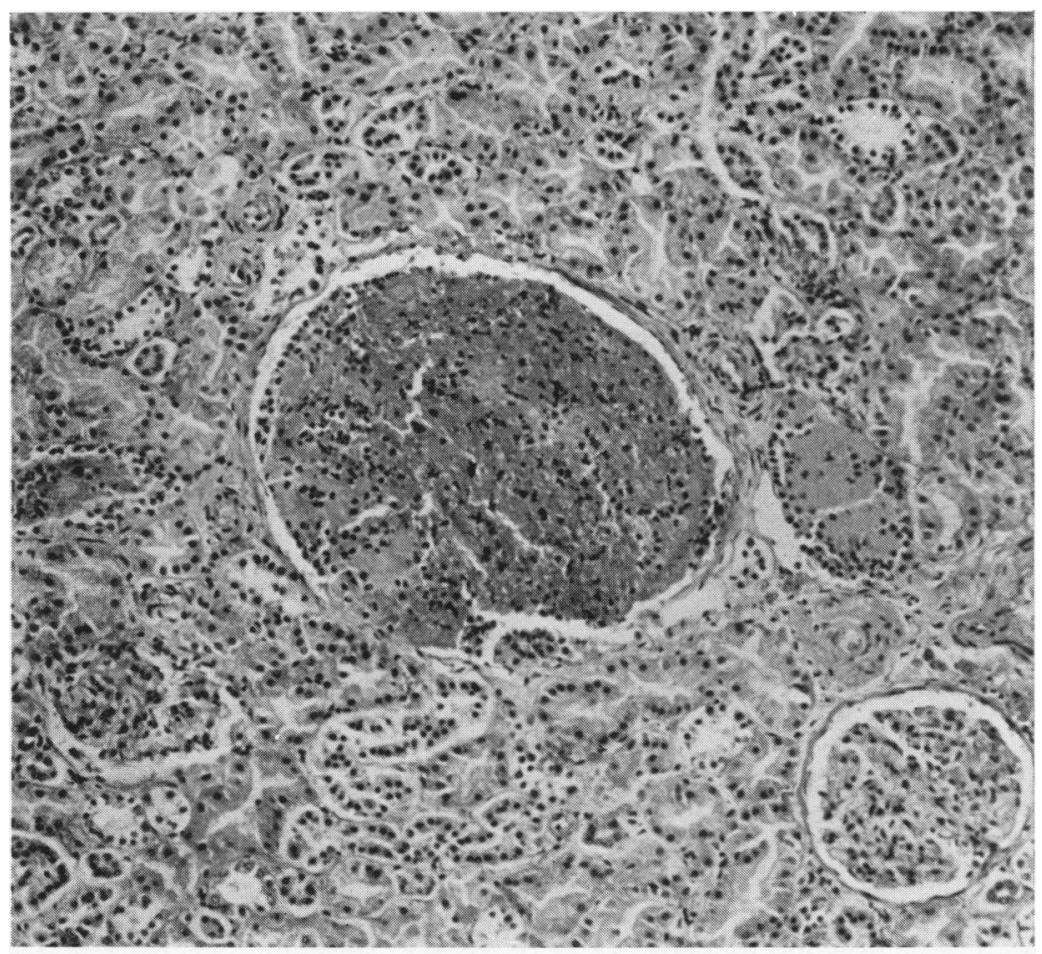

FIG. 12 .

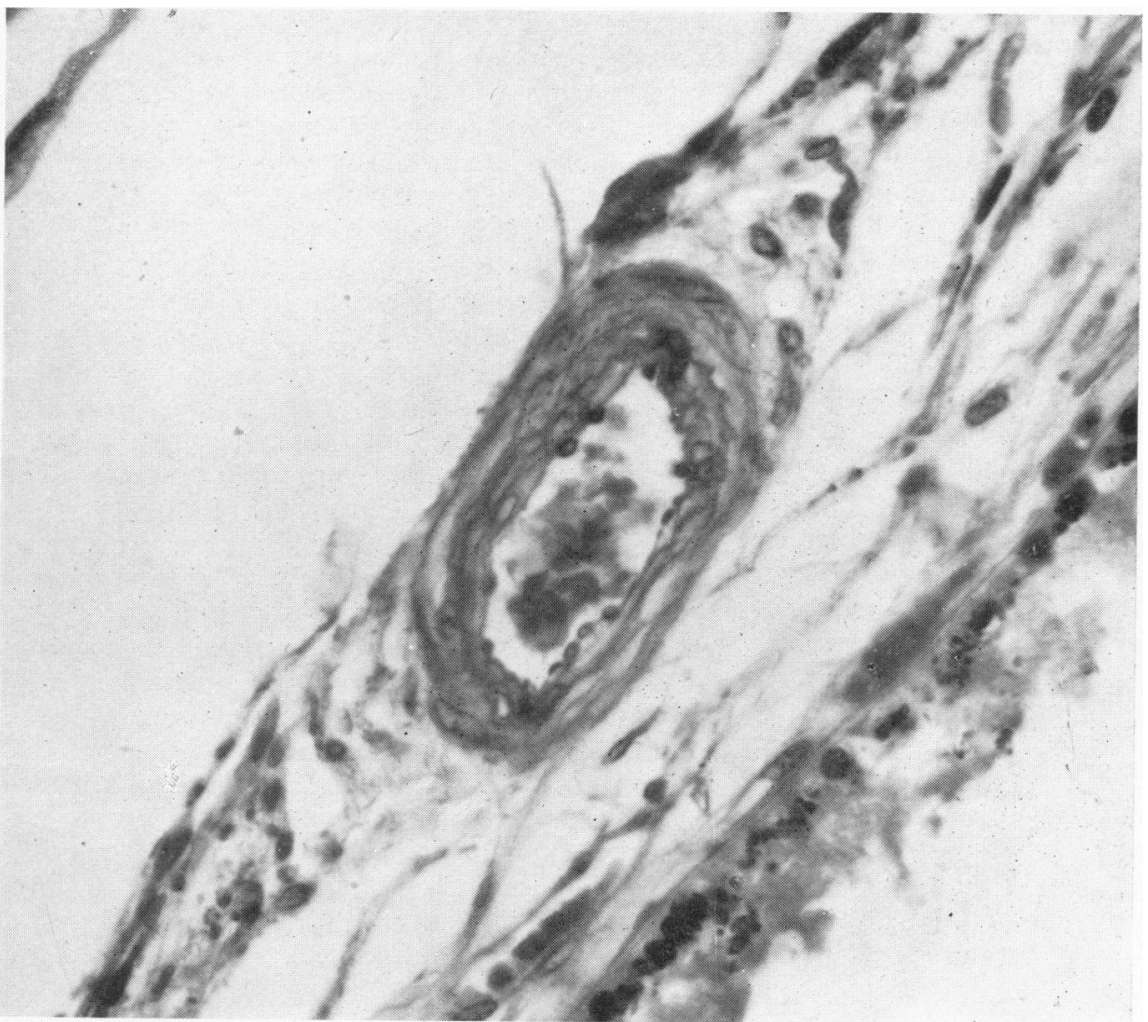

FIG. 13. 


\section{Discussion}

The characteristic paroxysmal attacks, with abdominal pain, vomiting, tachycardia, sweating, restlessness and collapse which the boy's doctor first described when his patient was 7 years of age disappeared when his blood-pressure became sustained. He was still liable to hyperadrenalinism on occasions which might have been expected to produce it: at times of emotional stress or by local stimulation to the tumour as in the injection of perirenal air. On examination by the visiting physician his face, hands and feet became a bright pink and the degree of sweating on his trunk was remarkable, the examining hands being literally wet. His irritability extended to the voluntary musculature, so that contraction of the abdominal wall always made examination difficult. It is now well recognized that the paroxysmal attacks may occur late in the disease (Cole, 1950), and that they may never occur at all; but that they may occur early, and then entirely disappear for three years while the patient remains comparatively well, as in M.B.'s case, is certainly unusual. It appears possible though not certain that the paroxysmal phase in this boy may have had some connexion with the massive retinal exudate which was the presenting sign in 1946. If this represented an extreme degree of hypertensive retinal change, it was certainly greater than is observed at any stage of essential hypertension in adults. It is remarkable that the retinal exudate regressed with the passing of the paroxysmal phase. Bruce (1947) paid especial attention to the retinal changes in the three children operated on by Cahill who showed exudate of much lesser extent than M.B., and he concluded that the fundal changes in these children were identical with those of essential hypertension in adults. Mr. Affleck Greeves, who saw him two years after the fundal changes had subsided, gave his opinion that the ophthalmoscopic appearances were those of a healed choroiditis. This was not, however, the opinion of several ophthalmologists who saw the boy in 1947.

The clinical diagnosis of phaeochromocytomata in children should present little difficulty if the sphygmomanometer is used routinely in their examination. The boy's appearance was so remarkably like that of a baby with pink disease as to suggest that hyperadrenalinism may play a part in the mechanism of acrodynia, in which restlessness, irritability, pink extremities, sweating, hypertension, and tachycardia are also cardinal signs.

The benzodioxane test has recently been exposed to some criticism because it has occasionally failed to yield a positive result when phaeochromocytomata are present (Roth and Kvale, 1949; Prunty and Swan, 1950); because it has occasionally yielded a positive result when other conditions are the cause of the hypertension (Taliaferro, Adams, and Haag, 1949); and because serious side-effects are sometimes produced $(12 \%$ of the 75 cases of Wilkins, Greer, Cuthbertson, Halperin, Litter, Burnett, and Smithwick 1950). It provides, however, an indispensable confirmation of diagnosis, and it has a degree of specifcity unusual in most clinical or laboratory diagnostic examinations. No death has been reported from its use, and it has now been very widely used. The localization of the tumour is difficult, and may be dangerous. The injection of perirenal air, first utilized by Cahill, is a method of great value but it may fail to locate tumours in the adrenals, and it has only once located an extra-adrenal tumour. It is not employed in the Mayo Clinic for localization of adrenal tumours on account of the dangers of the method; it is probable that the danger is inversely proportional to the experience of the operator, and Cahill has continued to regard it as safe and reliable. The alternative method is the diagnostic laparotomy, and since this caused the death of M.B., it would appear wiser that, in future, any tumours discovered should be removed at the first laparotomy.

Spear and Griswold (1948) showed that dibenamine hydrochloride (N,N-dibenzyl-betachlorethylamine hydrochloride) would depress the blood-pressure in phaeochromocytomata for 11 hours, after which the pressure rose to previous levels. Koffler et al. (1950) have recently confirmed the action of dibenamine in a boy. Grimson, Longino, Kernodle, and O'Rear (1949) report a successful operation in a boy aged 10 in whom they injected an adrenalytic substance (C7337) six times during the operation to prevent the fluctuations of blood-pressure which occur during the operation. Our experience with M.B. suggests that this is one of the ways in which surgery may be made increasingly safe for these patients. The post-operative collapse which follows the removal of these tumours is well recognized. Professor H. J. Burn (personal communication) states that this collapse is due to the depression of impulses through the sympathetic ganglia by the discharge of adrenaline throughout the operation, so that the normal stream of tonic impulses is unable to reach the blood vessels.

The action of such substances as benzodioxane was thought to be adrenalytic, but it is now believed that they compete with adrenaline and allied pressor agents by occupying the adrenaline-specific receptor. The action of benzodioxane is transient, but dibenamine is thought to combine irreversibly with the adrenaline-specific receptor. Both Goldenberg 
(personal communication quoted by Prunty and Swan, 1950), and Howard and his colleagues have found that benzodioxane blocks the specific receptors for both adrenaline and nor-adrenaline. Prunty and Swan (1950) have recently reported their results in the use of benzodioxane in a series of normal subjects undergoing adrenaline and noradrenaline infusions. The fall in blood pressure was transient and inconsiderable, and both tachycardia and vasodilatation occurred. They suggested that the increased cardiac output in their cases may have more than balanced the pronounced vasodilatation. Such a mechanism may explain the occasional failure of the test with benzodioxane in the presence of phaeochromocytoma. It is apparent that the blocking action of adrenalytic substances, and the effects of adrenaline and nor-adrenaline on the circulation both require further elucidation.

Pamela Holton at Oxford (1949) was the first to identify nor-adrenaline in these chromaffin tumours, and she suggested that it might be the cause of the paroxysmal attacks since it has a greater pressor activity than adrenaline. Adrenaline causes vasodilatation with increased cardiac output and consequent hypertension; nor-adrenaline acts as a vasoconstrictor without effect on cardiac output. The hyperglycaemic effect of nor-adrenaline is less than that of adrenaline in the ratio of $1: 8$. It is thought that the content of nor-adrenaline in the secretion from the healthy adrenal medulla is less than 20\%. Goldenberg and Faber (1949) have shown by chromatography that 50 to $90 \%$ of the adrenaline fractions of these chromaffin tumours was composed of nor-adrenaline. These observations have been confirmed by subsequent workers.

A notable advance in the diagnosis of phaeochromocytoma has recently been made by von Euler in Stockholm. By a biological estimation of the catechols in the urine, he and Engel (1950), have shown that the output of urinary adrenaline and urinary nor-adrenaline is greatly increased (normal 20 to $40 \mathrm{mg}$. a day) when a phaeochromocytoma is present.

The endocrine side effects of the tumours are interesting, but difficult to explain. The hyperglycaemia (as demonstrated in M.B.) has been suggested to be due to stimulation of pituitary hormones by adrenal cortical activity. It would seem easier to attribute it to continuous mobilization of liver glycogen by adrenaline. The evidence provided by the output of urinary 17-ketosteroids in M.B. suggests that there was adrenocortical depression. This was accompanied by a low output of gonadotrophins, and Dr. Hain suggested that both these results may be explained by hypopituitarism. Adrenaline (Corcoran and Page, 1948) stimulates the production of adrenocorticotrophic hormone by the anterior pituitary. Koffler et al. found a high output of gonadotrophins in the urine of their patient. The child aged 2 years described by Neff et al. had evidence of hypercorticism in the presence of a phaeochromocytoma. It is apparent that these assays, though interesting to record and to speculate upon, cannot yet be understood.

\section{Summary}

A case is described of multiple phaeochromocytomata (four tumours) occurring in a boy aged 11 . A characteristic paroxysmal phase lasted from the age of $6 \frac{1}{2}$ to 8 years of age. For a further three years the boy was in good health, except for symptoms of sweating, restlessness, nocturnal enuresis, and occasional fatigue. This was the phase of sustained hypertension. The third phase of hypertensive heart failure would not have been long delayed if he had not died after a diagnostic laparotomy. The clinical signs and electrocardiographic changes of advanced hypertensive disease were confirmed by the state of the arteries and arterioles at necropsy.

References are given to other examples in the literature of phaeochromocytomata in children diagnosed during life.

Massive retinal exudate was coincident with the hypertensive phase. The amount of exudate was much greater than has been described either accompanying phaeochromocytoma or essential hypertension. The exudate regressed during the phase of sustained hypertension. The retinal changes were associated with a pleocytosis in the cerebrospinal fluid. Expert ophthalmological opinion is not agreed as to whether the changes in the fundi were related to paroxysmal hypertension.

The benzodioxane test gave a positive result in this boy, but the injection of perirenal air was not completely successful.

The diagnosis of these tumours is easier in children than it is in adults, if the repeated use of the sphygmomanometer is not forgotten.

The excretion of gonadotrophins and 17-ketosteroids was low in this boy, and the significance of this fact is discussed. The pharmacological nature of the tumours is described.

I am grateful to Dr. A. M. Hain for the endocrine assays, to Professor H. J. Burn for some advice in pharmacology, to Mr. A. J. Wilson for his surgical help, to Dr. I. Mackenzie for the necropsy reports, to Mr. T. E. A. Carr and Mr. Affleck Greeves for access to their ophthalmological records, to Dr. G. Q. Chance for radiological reports and to Dr. Watkins, my house-physician, for some bedside investigations. 


\section{Bibliography}

Bruce, G. M. (1947). Trans. Amer. Ophthal. Soc., 45, 201.

Cahill, G. F. (1948). J. Amer. med. Ass., 138, 180.

Calkins, E., Dana, G. W., Seed, J. C., and Howard, J. E. (1950). J. clin. Endocrinol., 10, 1

Cole, L. (1950). Brit. Heart J., 12, 232.

Corcoran, A. C., and Page, I. H. (1948). J. Lab. clin. Med., 33, 1326.

Engel, A., and von Euler, U. S. (1950). Lancet, 2, 387.

†Espersen, T., and Dahl-Iversen, E. (1946). Acta chir. scand., 94, 271.

Evans, W. F., and Stewart, H. J. (1942). Amer. Heart J., 24, 835 .

Evans, V. L. (1937). J. Lab. clin. Med., 22, 1117.

Goldenberg, M., and Faber, M. (1949). J. clin. Endocrinol., 9, 652.

†Grimson, K. S., Longino, F. H., Kernodle, C. E., and O'Rear, H. B. (1949). J. Amer. med. Ass., 140, 1273.

Holton, P. (1949). J. Physiol., 108, 525

Koffler, I., Buck, G., Wingard, C., Hitchcock, P., Guthrie, R., and Teague, R. S. (1950). J. clin. Endocrinol., 10, 897.

†Linneweh, F. (1942). Mschr. Kinderheilk., 90, 179. Quoted by Snyder and Vick. $\nmid$ Litman, N. N., and State, D. (1949). Pediatrics, 4, 735 .

† McCoy, G. E., and Bridgeman, M. L. (1950). Ibid., $6,286$.

Mackeith, R. (1944). Brit. Heart J., 6, 1.

+Neff, F. C., Tice, G., Walker, G. A., and Ockerblad, N. (1942). J. clin. Endocrinol., 2, 125.

Pitcairn, D. M., and Youmans, W. B. (1949). Fed. Proc., 8, 127.

Prunty, F. T. G., and Swan, H. J. C. (1950). Lancet, 1, 759.

Roth, G. M., and Kvale, W. F. (1949). Mod. Conc. cardiovasc. Dis., 18, 41.

†Snyder, C. H., and Vick, E. H. (1947). Amer. J. Dis. Child., 73, 581.

Spear, H. C., and Griswold, D. (1948). N. Engl. J. Med., 239, 736.

Taliaferro, I., Adams, R. A., and Haag, H. B. (1949). J. Amer. med. Ass., 140, 1271.

Wilkins, R. W., Greer, W. E. R., Culbertson, J. W., Halperin, M. H., Litter, J., Burnett, C. H., and Smithwick, R. H. (1950). Arch.intern. Med., 86, 51.

(Description of phaeochromocytoma in children diagnosed during life marked with a dagger.) 